\title{
Moderator: $\mid$ Nexus 2002 Round Table Discussion: Judith Flagg Mathematics in the Architecture Curriculum
}

Moran

Panelists:

Jean Brangé,

Stephen Wassell,

Maurizio Vianello

Arsélio Martins, Mario Krüger
The round table discussion on mathematics in the architecture curriculum took place at the Nexus 2002 conference, 17 June 2002. Moderated by Judith Flagg Moran, panel members discussed issues pertinent to teaching mathematics to architecture students. This paper is the transcription of the audio tapes made of the discussion.

JUDY MORAN: The questions [for the round table] address the role of mathematics in architecture education. We originally had four questions:

- Is mathematics a necessary part of the education of an architect?

- What effect does the increasing use of computers have on the mathematics that an architect needs to know?

- What kind of skills are required at the secondary level to prepare students adequately to prepare students to do architectural work at university?

- What role can architecture play in mathematics education?

The fourth question, What role can architecture play in mathematics education?, we have actually sort of shelved as maybe not as fertile, although I think that Steve Wassell is going to address that a tiny bit. And one other question suddenly seemed very paramount, and that was the assumption that we knew what we meant when we said "mathematics" and that's what I would like to talk about a little bit and then the panelists will each take about 5 or 6 minutes to talk about address one specific area of those questions. We'll have a little conversation among ourselves and then jump in with both feet and have a bigger conversation. I am not only not an architect, Trinity College has no architecture program, I'm not involved in the education of architects, but I've been listening real hard for two days and what I have heard, I really enjoyed Lionel [March]'s paper so much of course, as a mathematician, but what I'm hearing is lots of mathematics involved but not so much what we have traditionally have thought of, or what I have come to the meeting thinking of, proportion, although that's certainly still very important, in lots of papers we talked about that; geometry (I am a geometer, by the way, I work in filling space, tiling, so I guess that's my tie to this group); calculus; number and relationships of number, and we've heard papers, some very wonderful paper, addressing those ideas, but we've also heard of branches of mathematics that we might not have thought of: graph theory, because that's the branch of mathematics that describes connections, so if you want to know how to connect all the parts of your building, graph theory can be very useful in modeling. Combinatorics, which Lionel used to enumerate all the possibilities of solutions; group theory, to distinguish the different kinds of configurations, that could be very useful; topology, a fairly new branch of mathematics, only about a century old, which talks about distorting spaces while maintaining their connections, and 
with some of the more unusual spaces we're seeing in architecture now topology is also a good language to describe some of what we are seeing and maybe a good tool with which to conceptualize which is what I think a lot of this mathematics can serve. Also, I don't want to leave anything out because my colleagues reinforced this for me. We heard of the importance of logic, to several people in their discussions. We talked about shape grammars and I know Andrew IKang Li talked about shape grammars and he also gave mathematics a very lovely compliment when he said he wanted to think mathematically and then he clarified that and said he wants to clarify precisely what he means. I think mathematics (of course I am a mathematics) but I think mathematics is very, very good at that. When we are talking about mathematics I'd like you to try to keep your mind open to all of those areas which you may not have thought of instantly as mathematics and I forgot one, which actually Jean [Brangé] and I were talking about, because he was talking about using a lot of data as input because he is going to talk about using the Internet and the new ways we think as a result of that and I said, "If you are going to deal with a lot of data what about statistics and data analysis have to do with that?" and he said, "A great deal." So there is yet another math topic.

We agreed on what we were going to attack in our discussion and Mario Krüger has some slides to show and he is going to talk about the [architecture] program at Coimbra, the curriculum there and what they have done, what he feels they have done well and the problems.

MARIO KRÜGER: I am just going to do a short presentation, it is not going to be a paper at all. But I will start by speaking about two leading psychologists, which have in the last ten or fifteen years led the debate on education and I mean Jean Piaget and Lev S. Vigotsky. I'm not going to talk about their proposals but I'm just going to say that, first, Jean Piaget says, in my own words, "Always transform, don't imitate" and Vigotsky says, "Always interconnect, do not isolate". I'd say that we've got two architects that speak exactly in those terms. One is Álvaro Siza. He says, "I don't create, I always transform." And I remember quite well Leslie Martin saying in another sense, the sense of Vigotsky, not in the sense of Piaget, "Always connect." So what I am going to speak about, the curriculum in the University of Coimbra at the Department of Architecture, which is inside the Faculty of Sciences and Technology, is about connections on the one hand and, on the other, of transformations. 


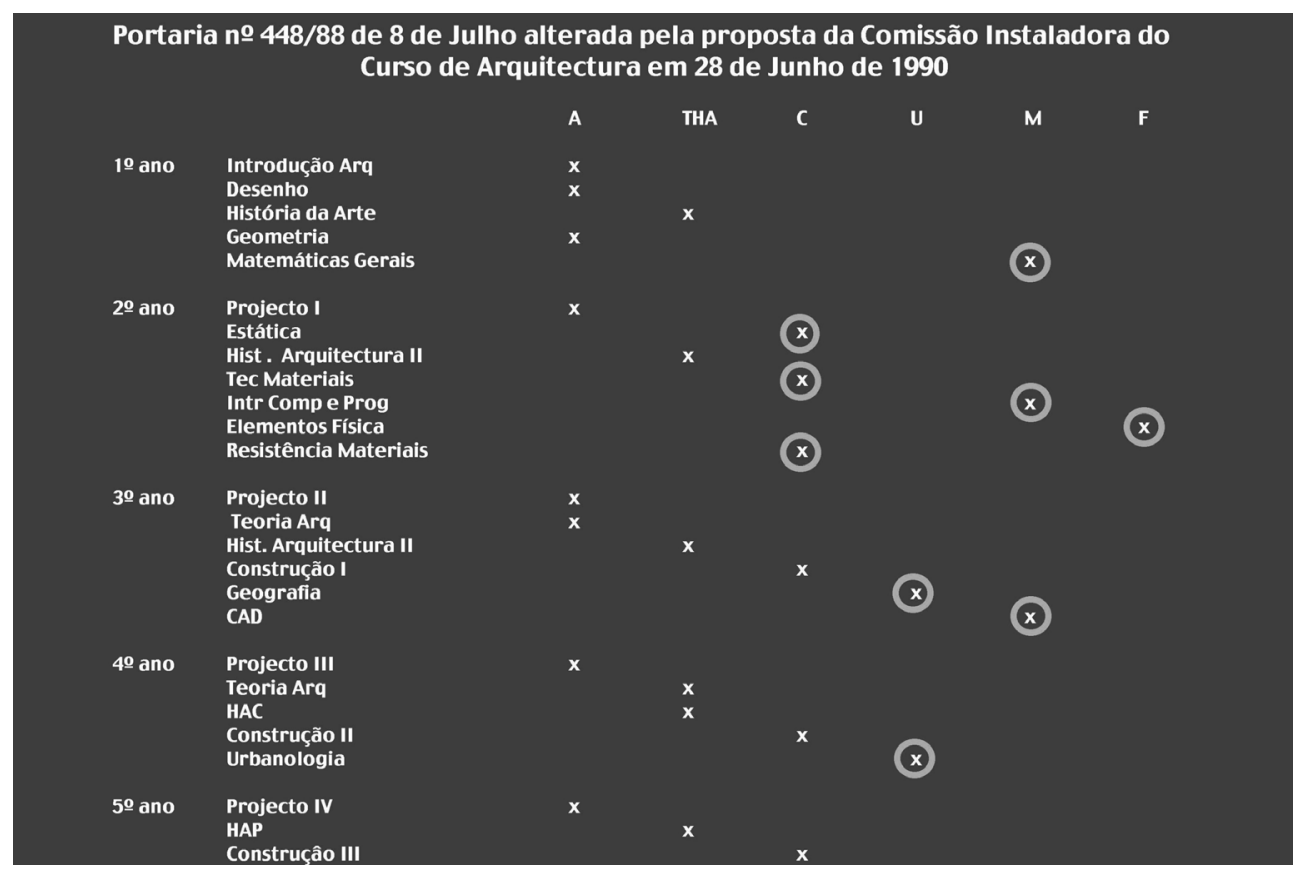

Fig. 1. The initial curriculum at the faculty of architecture, University of Coimbra. Vertical lines are arranged according to year (first through fifth); horizontal lines are arranged by areas: architecture, theory and history of architecture, construction, urbanism and planning, mathematics and physics. The circles represent the disciplines that were taught in other departments

First slide, please (Figure 1). So what you have here, I am not going to explain in detail, but just saying that we have the vertical lines arranged by years: first year, second year, third year, fourth year and fifth year and the horizontal lines arranged by areas: architecture, theory and history of architecture, construction, urbanism and planning, mathematics and physics. This was our initial curriculum at the school. These circles represent the disciplines that were taught in other departments and we felt very much uneasy about these disciplines because we didn't have control over them. It is a Faculty and as a Faculty we were forced to accept programs and professors from other departments as they were. So we decided to make a reformation in our curriculum in the last ten years and we can see that we have got in the old curriculum nine disciplines that belong to other departments (they are circled here). 


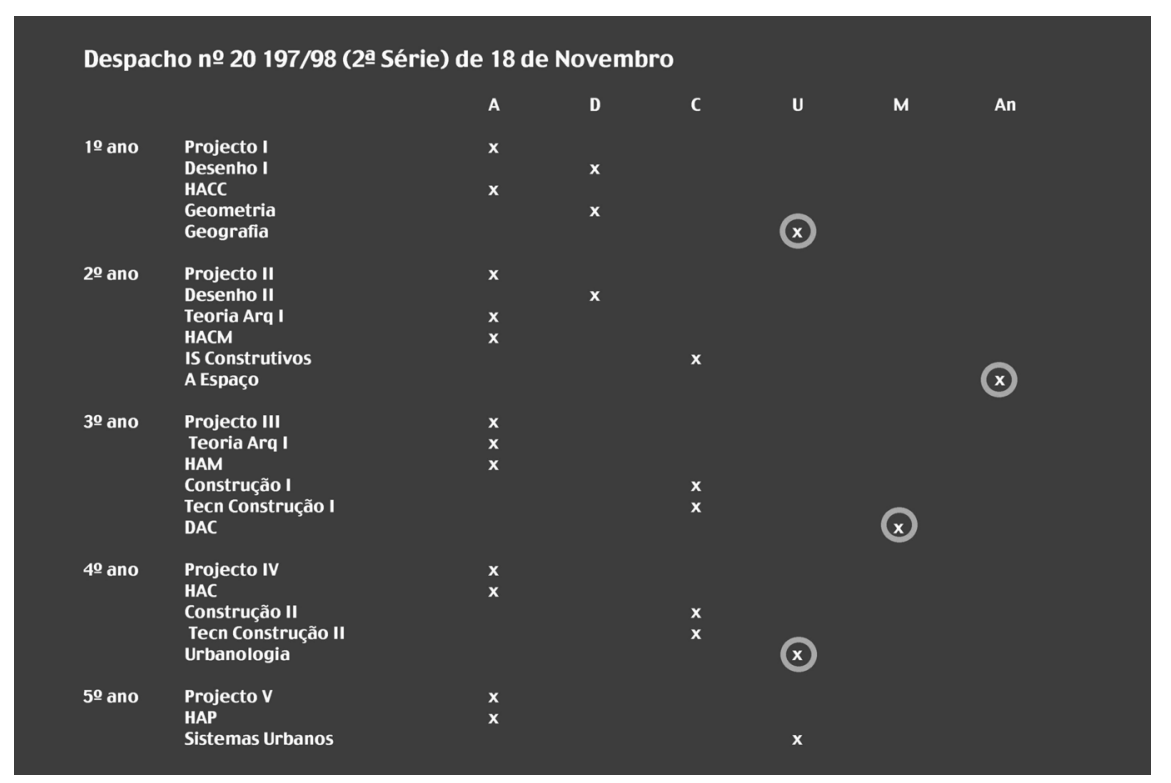

Fig. 2. The revised curriculum of the faculty of architecture, University of Coimbra. The new areas are: architecture, drawing, construction, urbanism, mathematics and anthropology. Four disciplines now covered by other departments and mathematics as such was dropped from the curriculum

Next slide, please (Figure 2). So in that reform, what happened? We have got these new areas: architecture, drawing, construction, urbanism, mathematics and anthropology. These are the areas that belong now to the curriculum. We have got just four disciplines now given by other departments and mathematics as such was dropped from the curriculum. It was in the first year of the course and it was dropped. And it was dropped basically because the professor of math, who belonged to the department of mathematics, she was very well intentioned, no doubt about that, but she got the wrong model. She went to Spain, to the School of Barcelona and she brought the curriculum of Barcelona to our school. I have to say that in Spain they don't have just architects as we do in Portugal and as happens in other European countries, where architects and building engineers are distinct professions. Generally it takes about ten to twelve years to do the course in Barcelona. They are at the same time architects and engineers, and we are just architects. So we felt very much uneasy about that and we dropped the discipline of mathematics. Also, the discipline of geometry still remains in the course. It is given in the Department. So it is about the new curriculum that I am going to speak about. Next slide, please (Figure 3). We can think it in terms of a full lattice representing the areas in the new curriculum. We have here at the bottom an empty set, we have there at the top a full set, and these in the middle are all combinations of the areas that we have now in the curriculum. For instance, the ideal situation it would be that one, with six areas combined together on the top of the lattice. Here you have one area related to each other, there the areas are more related and here is the new set which belongs to the new school curriculum. Next slide, please (Figure 4). 


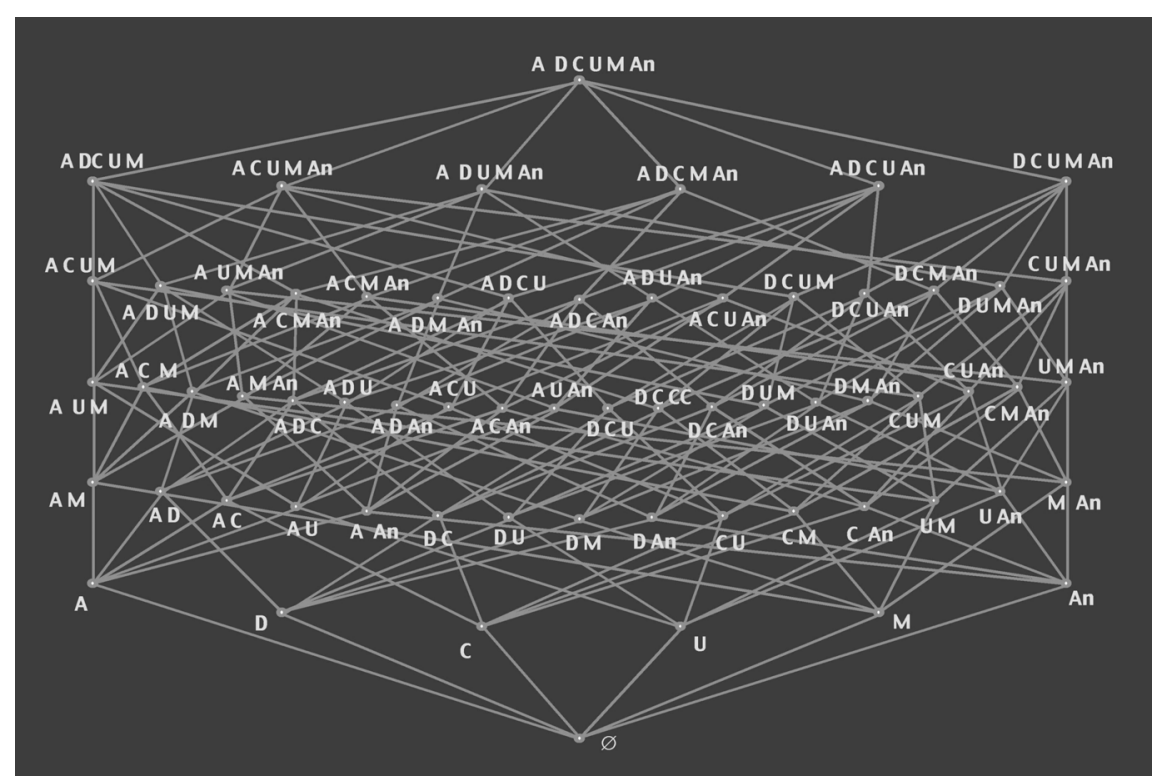

Fig. 3. A lattice representing the areas in the new curriculum in the faculty of architecture at the University of Coimbra. At the bottom is an empty set, at the top a full set, and in the middle all combinations of the areas now in the curriculum. The ideal situation it would be the one with six areas combined together on the top of the lattice

What we have got is a set of white lines that show the relationships that were made between the disciplines in specific areas: architecture, construction and urbanism. We were able through the years to make some connections between these disciplines. In red, what we have here are the relationships between anthropology and mathematics, which belong to other departments and we are not interested in developing these connections. So I would say that, of all possible connections and intersections that it is possible to have in the curriculum and not just of isolated disciplines, we are only working with seven percent of our full possibilities. So here, regarding Vigotsky (or Leslie Martin's dictum if you prefer) about "Always connect", we can be aware that we are not connecting the disciplines in the curriculum. So you it can said that in the end we are in a sense very much like an engineering course where the disciplines, as a whole, are very much fragmented and isolated.

Another thing is the entrance. I am not going to explain the whole picture here, but I will just say that to enter the school of architecture, given marks ranging from 0 to 20 , you need about 16.3 or 16.4 to enter architecture course in Coimbra. To enter mathematics course you just need 14.0 or 14.9 . So I would say that our students, although they don't have mathematics in the first year, are much more prepared to enter the mathematics course than the students who actually go to mathematics. That is the situation that is going on and that we are trying to change. 


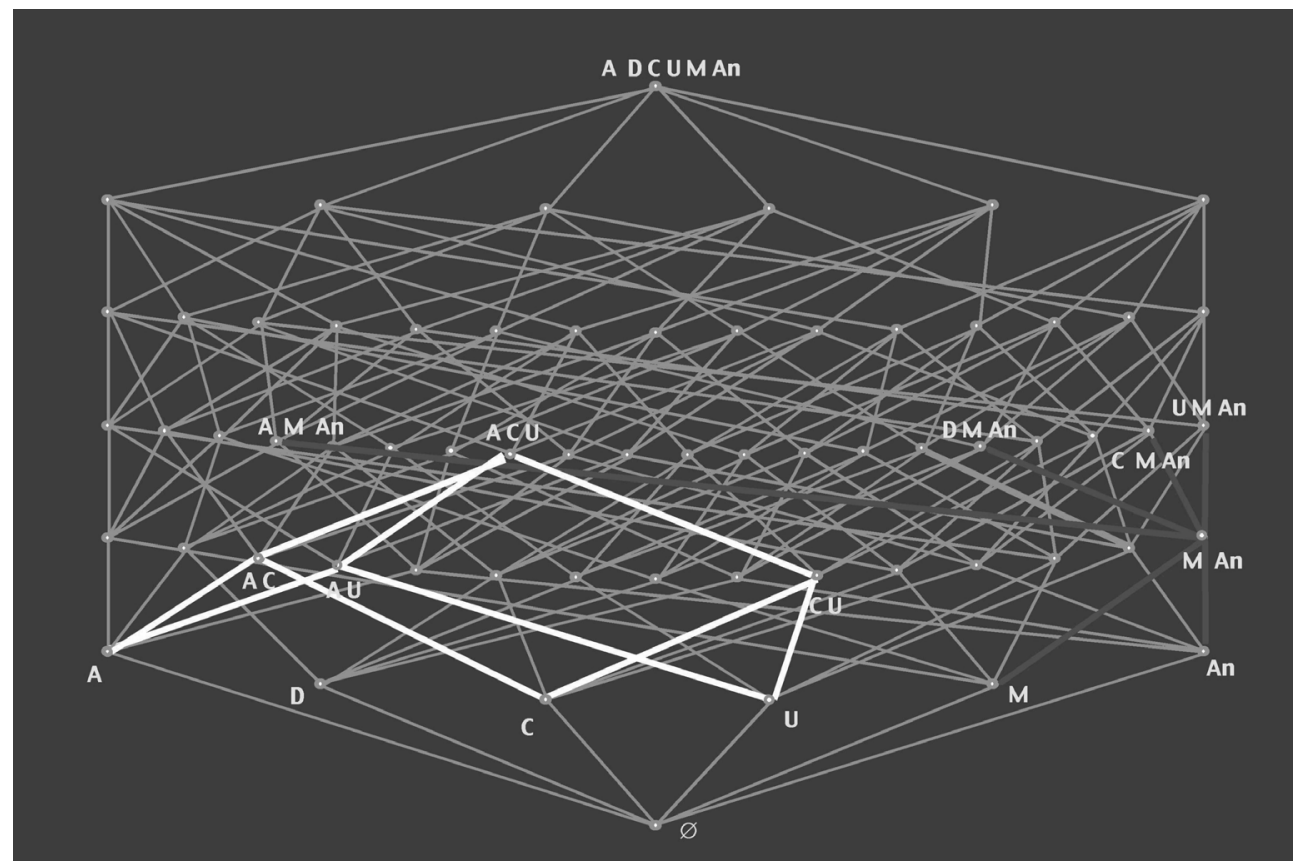

Fig. 4. A set of white lines that show the relationships that were made between the disciplines in specific areas: architecture, construction and urbanism. Shown in red are the relationships between anthropology and mathematics, which belong to other departments. There is no interest in developing these connections. It can be concluded that of all possible connections and intersections in the curriculum, not just of isolated disciplines, the faculty is only working with seven percent of its full range of possibilities

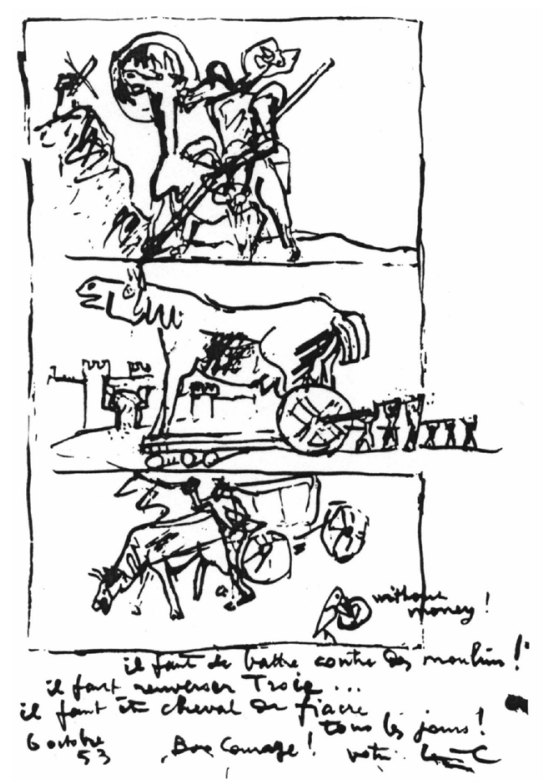

The next slide shows a Hieronymus Bosch painting (figure not shown), with all the kinds of things that we have just spoken about. I have to say that I have got a $\mathrm{PhD}$ in mathematical modeling, which was taken 34 years ago (Lionel March, at the time, was director of the Centre for Land Use and Built Form Studies in the University of Cambridge) and according to university regulations I am not allowed to teach mathematics, because I don't belong to the department of mathematics, which has control of the discipline of mathematics. So that picture of Hieronymus Bosch is not far away from the things I am saying.

Next slide (Figure 5). Although this is happening I have always a bit of hope. Let us look to a drawing made by Le Corbusier in 1953, I believe. He is just quoting Don Quixote fighting against windmills and things like that and also showing the Trojan horse and the chevaux de fiacre. Here (Don Quixote) is a situation 
which we can find at our university, which is to fight against all the bureaucracy that is going around. Here is a Trojan horse that we are trying to implement with that idea of Le Corbusier, when in fact we do mathematics but as optional disciplines. I give that type of knowledge as disciplines within the course, but with a disguised name. I call it "theoretical architecture". Space syntax, architectonics, land use and built form studies and shape grammars in the fifth year are taught by myself. And that is a way of dealing with these things and getting the students to use mathematics to think about architectural problems. So I am not totally without hope about changing the curriculum because we think it is possible to solve these problems. It will take time but I believe we are going in the right direction. We are going to change the curriculum, not university regulations, but things slowly and step-by-step are going in the right direction.

JUDY MORAN: I am going to ask Arsélio Martins to speak next. He also has some very firm ideas about what he thinks could be incorporated in the curriculum. He is going to address the secondary level, talk from his experience as a secondary level mathematics teacher here in Portugal, about preparing students to become students of architecture as well as consumers of architecture, so I think he is talking about everybody.

ARSÉLIO MARTINS: Thanks a lot. We are in trouble in Portugal because there is not just a problem with the university, there is a problem with all education. Here in Portugal the faculties and departments have left the mathematics out of the courses of architecture, while at the same time at the high school and secondary levels it is possible that students of arts and architecture haven't mathematics at all. The two movements are the same: they complete the cycle. In Portugal it is possible that an architect can't understand an article that explains how the Tacoma bridge fell. It's possible and it's awful. We think that the teachers in university and the teachers of math in high school have left mathematics out of their lives and so as a consequence the politicians can make these policies. I think that students of architecture need to know the core curriculum in high school just like the other students. They need to know geometry, but also coordinate geometry and vectorial geometry; they need to know calculus, and what it represents. They need to know functions, they need to know variations, they need to know all the elementary calculus of high school.. That is what I think: nothing more, nothing less. They need to know how to work with functions as outputs and inputs and to understand something as simple as a graph, a dependence between two variables. I don't understand how it's possible that university accepts students in architecture without these mathematics. They need to know the science of data, statistics, heuristics, combinatorics and I think above everything that they need to know other things than the other students. I think that the students of arts and architecture need to understand how computers work. They need something about matrixes, animation, transformation. Although I don't know how, it is possible that they could learn that in high school. I think it is possible that for students of architecture it is essential that they learn something about graphs, something such as rigidity of frames, something like degrees of freedom [tolerance] in tensors, constructions of walls, grids, frameworks. I am sure that it is important for students in these areas to know something about construction. Morris Klein writes that perspective, coordinate geometry, projective geometry are subjects of mathematics and that the history of painting of the Renaissance is a subject of mathematics, even a subject of high school mathematics. I think that it is important to teach it to students of mathematics at the secondary level. We feel that the times are not good to us, that these are bad days and bad years, but perhaps the next years will be better.

JUDY MORAN: Let's hope so! There are going to be a lot of things to comment on, I can see. Now with Maurizio Vianello we are in Italy. Maurizio is actually in the trenches teaching 
mathematics to architecture students. So far we've heard two takes on this. We had Mario wanting to teach mathematics and how he sort of subverts his school's structure so that he can do it, and we heard Arsélio talk about what he feels students should come to Maurizio knowing. Maybe you can talk to us, Maurizio, about then what happens. Also because there is certainly a difference in what constitutes a degree of architecture in some countries, which Mario made really clear when he talked about someone coming to teach mathematics in his school whose background was actually in Spain where that degree is combined with a civil engineering degree, which obviously has different requirements. Maybe you could mention a little about what that [architecture] degree entails in Italy.

MAURIZIO VIANELlO: I am a mathematician. I spent most of my life as a professor at the Polytechnic in Milan actually teaching mathematics to engineering students. Then a few years ago, maybe four years ago, it happened that I had this opportunity, call it an opportunity, to go and move to the architecture faculty, to become a member of this architectural school because the Polytechnic, as most polytechnics in the world, has two types of students: engineering students and architects. And of course that is a very common situation. In Italy you go there because we have this curriculum where there is mathematics in the architectural schools. Basically now things are changing in one or another direction but traditionally we had this kind of two years, one course first year, 120 hours, complete course including recitation classes and everything and then one full-year course in the second year. Now there are some changes, but I don't want to go into that because it is too specific to Italy. And of course the situation is that traditionally we are required to teach essentially what is a basic course on linear algebra, calculus and then something on curves and surfaces in space and even of course a few ideas about differential equations, at least the concepts. And the common feeling of course is that you go there and then your colleagues at the mathematical department pat you on the back and say, well, now it's your turn and because people aren't very happy to go to teach in architecture the idea is that most students don't have the right attitude. They don't accept the technical content of mathematics and the difficulties that are implicit in mathematics. That is an interesting problem because what I have found that the students are not so bad, actually, they are even appreciative, but they have the feeling that what you are teaching to them is not going to be useful. At the beginning of course they believe because of course they are naive, because they are first-year students. And there are bright students who are interested because they understand, if you teach well, that mathematics is an important part of human culture, and actually sometimes they appreciate more the abstract parts of what you are teaching because they understand that there are sophisticated concepts behind that, rather than the idea of when you pretend that you are teaching them something instrumental, because they start to have the feeling that it is instrumental to nothing, for them, for them of course. But what happens is this: in Italy there is a part of the curricula that is based also on the contribution of structural engineers, who teach statics who teach the science of construction and then once in a while they write a few equations because even they realize that students don't need to do real computation and to discuss in detail the equilibrium equation of a beam or whatever. But still they in principle they use some kinds of equations, they write a derivative every once in a while, they write this equilibrium equation of a beam, and because of that you are somewhat forced to give the students the basic knowledge so that they can understand this. So this is this huge construction that is based on the idea that a few people are going to use mathematics and you have to teach that. And this is the situation, but then what I realized, because I am not a fanatic, I like mathematics but I am not the type of person who wants to teach epsilon and deltas and all the details, my formation moreover is not as a pure analyst but as a mathematical physicist so I am oriented towards applications. And then you start asking around, you speak to your colleagues

88 NeXus 2002 Round TABLE - Mathematics in the Architecture Curriculum 
who teach in your school, and you try to ask them "What kind of mathematics should I teach?" and most of them don't know, they can't give you an answer, because most of them respect mathematics for the cultural content that it has, they see you as someone who has something like an esoteric knowledge of a very technical subject which they respect because it is very important from a cultural point of view, and they accept that you teach this to the students because you make them more sophisticated intellectually. But they can't answer you. Maybe one can say perhaps we should start teaching them with examples from architecture. This can be done of course, but if I go there and start teaching them from certain things that I heard here [at this conference] that would be a very touchy question, because then they would start saying "You are touching on our turf, you are trying to interpret architecture." Most of the talks that I heard here if I were to go and try to tell the students, well I heard this and if I make an example well that's okay and I've done that because I've come to this meeting other times because I had the opportunity to have feedback and some nice ideas to explain to the students occasionally, but I can't do the course much different from what I do. Let me just say one more thing. This is a very old story; there is problem between some kind of cultural environment and mathematics. (I want to add this because Kim Williams said that she likes arguments.) I don't want to start an argument, but it is a very classic stereotype: basically there is a problem with mathematics in a certain curriculum and what do you do? You try to kick out the mathematicians and then you do mathematics under another name because you do it yourself, and that is a very old part of the academic fight. It's an old story and not a very nice one. I get mad when this kind of things happen in my faculty, I say, "Well, if you don't want mathematics, but if you do you have to recognize that you need mathematicians. I agree however that for some reasons sometimes mathematicians are hard to manipulate, they are not very flexible, that's the problem with mathematicians, they are a bit rigid. However, later on maybe I can say something more about this.

JUDY MORAN: Thank you Maurizio [general applause].

MAURIZIO VIANELlO: I want to add something just to give an idea. How many people here in this room are first of all mathematicians by training, they have a degree in mathematics, not in architecture, and have experience in teaching architecture students? Ah, so quite a few, quite a few. So later we can see if you agree with me.

JUDY MORAN: As long as we're in the spirit of controversy, or spirited discussion, what I am going to do is keep Steve [Wassell] for wrap-up and ask Jean Brangé to talk. Jean is an architect but does in fact teach students in an architectural school. He is speaking tomorrow about using computers and the Web in his work, but he's going to talk about what we mentioned earlier, how computers influence what mathematics is required and how it's presented. It seems like after Maurizio's impassioned address this will keep the blood running!

JEAN BRANGÉ: The main point I would like to introduce is the way our world has been changing the last fifty years. We are seeing these changes mostly in the last few years, but the changes have been going on for quite a long time, and these changes are being transmitted through the computer, the networks, the Internet and the way we exchange information, to produce information, to produce our work, to look at ourselves and how we have also changed as human beings in a different space, so space has changed and human beings have changed, and our relationships have changed. So given this, of course the way we teach students have changed. First of all, we have different international backgrounds, all different experiences, but these experiences are getting more and more connected. Why? Through the Internet. This [meeting] is only possible through the Internet, it could not have been organized so easily without these things, so 
we wouldn't be here discussing. There would be people discussing in the United States and other people discussing in Europe, and we have different views or experience, this would not happen, so this has changed things. And so has the way that people are being taught. The students themselves are not the same, they are not the same as we were, they are really different because they were born in this new media/technology/computer networks, etc., which for us we had to learn and implement and go through a lot of steps, they just start at a much higher level than we do and a lot of things are granted for them that are not for us, so we have to explain much more than they think we should (which doesn't mean that we shouldn't explain these things to them, which is another problem). I would like us to think about this, how we change our teaching. So regarding this, for example, mathematics is changing, so of course the enumeration that you made for me, all these theories are relevant for architects. All architects would not use all these, but in a school it is interesting to show people that these exist and some people will be going into these directions and will be testing these things. But this is only math and there is also philosophy and other disciplines or so. The computer that we use is a tool that gives us a mediation between the techniques or the fundament that we use and the way we use it. So people are using mathematics without knowing it and we have to be careful about what it means, so we have to know when to explain, but we can see too, must we always explain? Can we just use it without, for example, always understanding? A very simple example we can think about is a car. If you wanted to drive a car eighty years ago, you had to be everything, driver, mechanic. Now you don't need to be everything, you cannot. If you open the hood, there is a computer inside that resets itself to zero and you can't interact with your car, so it's not that you should not, it's that you cannot. But this doesn't mean that we don't drive cars; we drive cars better than ever, and more people drive cars and are able to do things than every before. So what I want to say is that more and more people and students are using mathematics but maybe without knowing it, but we've been doing things with it in a much better way than they may have been able to do before. Why not? That's a question that I think is open and I think that the possibility depends on how we teach them, how it is eaten or not eaten and you can get through the different layers and of course the computer and the network and other things, cellular phone, fax, is very important new phenomena, and there are lots of other questions that we can talk about.

JUDY MORAN: Thank you, Jean. Steve is an American who teaches at Sweet Briar College in the States, and Steve is a very good clean-up batter because his undergraduate degree was architecture and his Ph.D is mathematics. He teaches mathematics at Sweet Briar. He doesn't teach architecture because they don't have an architecture program, but in fact he certainly speaks from the experience of having architectural training. He actually has thought about ways that tools for thinking about space and shape can be incorporated really early into the curriculum.

STEPHEN WASSELL: I'll keep my address brief because we really do want to get participation from the audience as well. The one question we cancelled was the one I felt I had real expertise in, unfortunately, so I'll give that a few minutes, which was the possible role of architecture in the mathematics curriculum. I don't see all that much of a role, and I'm certainly welcoming a different viewpoint there, at least at the college level. There are courses that you can teach in college especially courses for the non/mathematician, where you can use examples from architecture, but I don't think there is as much or a role for architecture in the math curriculum as vice versa. I will say that at the early ages I think there is a good role. Very young children can be turned on to architecture by exploring [questions such as] "Can you find these shapes in these buildings?" When you get on into middle school or high school working with basics of symmetry and even proportion can be certainly useful. If there are conflicting viewpoints there we welcome hearing them. As far as math and architecture, in my undergraduate experience we were required 
to take one course in calculus, one course in computer science, two courses (semesters) in architectural physics, and then we had half a semester of structures (you know that was almost twenty years ago). So one question I want to throw out to the whole group here is, Do you need calculus if you are going to be an architect? We've already heard some viewpoints on that, but it's an open question. Would it be useful to have other kinds of math, what you might call architectonics, shape grammars, or other topics? I teach a course at Sweet Briar called "Architecture and Mathematics". It's an interdisciplinary course, not a math course, you don't get math credit for it, and it's a writing-intensive class, not a quantitative-reasoning-intensive class. It's essentially a history of architecture course with towards viewpoint of mathematics so looking at proportion, symmetry and geometry in general. I don't get into architectural morphology or shape grammars and so forth as far as perhaps I should, but my experiences there went fairly well. So now, we want to hear from you [the audience].

JUDY MORAN: First I'll ask if anyone on the panel wants to respond to any of his colleagues?

MARIO KRÜGER: Yes, I'd like just to not exactly give an answer but give a comment, which is in essence, you don't know the University of Coimbra. So I invite you to come and see with your own eyes and see what is going on.

MAURIZIO VIANELLO: If I may answer that, obviously I didn't want to start a discussion on this detail, but there is a general problem, there is a tendency which I've seen at work many times to emarginate the mathematician and then steal the topics, basically to incorporate them. Because it is true on one hand that in many disciplines you find more and more mathematics, sometimes hidden behind the scenes. The reason is that mathematics is more successful a some sense but mathematicians are less needed, this seems to be the contradiction. But the problem with computers in my opinion, but the feeling that I have sometimes is, what I am afraid of, is that when you train someone to use a computer you are training a consumer basically. I don't want to start a political discussion about that or about Microsoft, but it's a question. People say that the students must be computer literate, I agree, because it is obvious to anyone. But in the same way, the students for their daily life today must know how to use a telephone or drive a car or many other things,, but universities never had the idea that they needed to teach how to use a telephone (but that's very easy, of course). I am saying this jokingly, but I believe in this, there is a problem behind this. I'm not saying that from a commercial point of view you are trying to tell someone to use a specific program from IBM or whatever. Even assuming that you use your own program or something in the public domain so that there is no hint of any commercial second thought behind that, but in a sense you have to be careful that you are not teaching someone to be a consumer of something made by someone else. That's what bothers me.

JEAN BRANGÉ: Yes, I will continue the controversy. I'm talking about this, trying to share my ideas in France for almost fifteen years, unsuccessfully. I'm trying to get __ for only two years so it took me a long time to get there. I am thinking of what you said: a computer is not just a simple tool. We just started a reform of the curriculum in the school, in which we had to make a distinguish between being computer literate and the computer as a tool, instrumentation, that is, how does a computer work and for this we give courses the first two years to be sure that all the students at the end of the second year can make 2-D drafting, 3-D models, produce something on the Internet, use the networks, send e-mails as well. This is not what I'm talking about. I'm talking about something that we do further at the school, in the fourth year, the year before the diploma, which is, "Why do we use computers?" Then we get students trying to ask questions of themselves and of the computers. Why do I use this? How do I produce something? Why do I want to produce this thing? What does it mean? I do not yet have a full-time position in the 
architectural school, I am just working at the computer graphics level, so I don't have much opportunity and I have to be very, very careful of what I teach, but the computer is not a simple tool. Are we in front of a new tool being used with the same concepts as before, or are we in front of new concepts and the tool is the same as before? I think these are changing. We have new concepts emerging, like in the Renaissance, and I think a lot of people would agree. The Renaissance and perspective in its globality, and also science and other fields were in a moment of big changes of the relationship of men with the universe and men with other people, to science itself, how we know, how we represent the world, how we create, how the design process itself was changed, and we are in the same kind of shift now, just that it's not the Renaissance, it's the atomic bomb and the Pioneer team, the team which is going into outer space. That's the shift we have today, and in this shift the computer is not just a simple tool. I'm going to say what you have heard 10,000 times in the last three years with globalization and so on, but this is there, we cannot say it's not there, cyberspace exists. There are people who are living in cyberspace today and they live there, they don't live where we live now. They are not here, they are out in networks, and these people are human beings.

JUDY MORAN: Thank you Jean. This might be a good time for someone who is actually an architect who wants to talk about using or not using computers.

JOSE FRANCISCO RODRIGUES: Before going on discussing computers, I think there is something more basic and fundamental to discuss. And in fact we had started the debate with the Coimbra experience, which reminds me of what happened in many other fields. I came from the University of Lisbon where we do not have architecture at all. We have, in the faculty of science, mathematics, physics, chemistry, biology. Let me give an example from biology. We have recently the same experience of mathematics in biology as the Coimbra experience with mathematics in architecture. Biologists do not like the kind of mathematics that we offered there, so they decided just to cut. I am really very much concerned how the faculty of science of biology at the university of Lisbon will be studying biology in the twenty-first century without knowing basic mathematics, this is something that is not possible. So, the question of basic training of architecture is, "What is the right measure of the scientific preparation that an architect requires in the twenty-first century?" Of course, I'm not prepared here to say whether calculus is fundamental or not. What I would like to say is twentieth-centuries histories is important, particularly for Portugal, and there is an recent interview with the well-known Portuguese architect Álvaro Siza. The interview was made by Luis Reis, who is here, the magazine was that of the Portuguese Association of Mathematics Teachers, and I would like to quote very quickly, and of course the interview is in Portuguese, about the question about what is important of mathematics, Álvaro Siza said that at a point in his studies of architecture, he was doing differential and integral calculus and he had a very good teacher and it was in an architectural school. But what was important about the interview especially was that though nowadays he doesn't remember anything, he feels that what was important about that learning was the habit of thought, the clarity of ideas, and he thinks that this came very much from his studies of differential and integral calculus. A little farther into the interview, came what was the importance of mathematics in the course of architecture. What is important for Álvaro Siza is the formation of our minds, discipline. And here came a crucial point, that I am not sure that just the geometry courses in the first year in the architectural curriculum, like in Coimbra, is sufficient to consolidate a minimum of scientific background for an architect. Of course, nowadays architects work in teams, and even Álvaro Siza says, afterwards it's the engineers, so we don't need to deal very much with numbers. Of course, the architect nowadays may not have to deal very much with numbers, I presume, because they work in interdisciplinary teams with engineers, maybe not with mathematicians, but with at least with 
designers and so on, but the point is, how can the architect make a profitable dialogue in a team if his scientific background is small? I don't know. The main point here is the right measure for the twenty-first-century architect, which is his basic scientific training. And I'm still wondering if it's still possible to give a basic scientific training in the twenty-first century without basic calculus. Even if they are not going to use calculus anymore in their lives, calculus has such an important role in our scientific development and it's still so important in a basic scientific mind, that I'm wondering if just classical geometry, just combinatorics, or graph theory, can be enough.

JUDY MORAN: I'd like to say one thing: don't say “just geometry”. At any rate, we often use a lot of calculus studying geometry, but we were talking about this, and in fact, Maurizio, you were talking about a course that doesn't exist, a book that doesn't exist that should exist, for teaching mathematics to architects, so I think this is probably his opening.

MAURIZIO VIANELlO: There are many, many things which could be discussed. I understand, because we talked before, that it is a bad thing that some fundamental notions of calculus should not be part of our cultural background of any learned person, because people are ashamed not to know Shakespeare, but they are not ashamed not to know the idea, not how to compute the derivative, but the idea of the derivative or many other basic concepts of mathematics. That's a big and serious problem. My position from that point of view is that I am available even not to teach calculus, I mean I don't come from pure analysis, so it is not in my genes from an academic point of view. But the point is that mathematics has its own methodology, so in the end I want to teach a course in mathematics, you can talk about shapes and graph theory, you can find many interesting things which could be taught to students of mathematics, but in the end the value of mathematics is that you start looking at a problem from observations, and then you model things and then you have an abstract structure; you have a precise definition and in the end the value is that you prove a nontrivial theorem. The students understand what it means to prove a theorem, which seems trivial, but it's not, because there are many people in society and even among university students who don't have an idea what a proof is. I get mad, not when the students don't know, but when they don't understand that what they are saying doesn't make sense from a strictly logical point of view, they are not proving anything. That is really the value of mathematics, that it can teach you, you learn by experience, you touch a bit of truth. Now I don't want to get into an epistemological discussion about whether mathematics is absolute knowledge or not, that would take us far away and I don't believe that in general. The other thing I wanted to say is that there are many, many books of calculus and general mathematics in Italy, of course I don't know the bulk of these publications, but I know a lot of the English literature and then you can clearly see that many of these calculus books and mathematics books are written for engineering students, the examples are clearly for the physical applications in the field of engineering, too much in that sense for an architecture student nowadays very much for the business and economic fields, because this is a big area and they can sell a lot of books. But I have never met a book which is really a general book of general mathematics, not a specific book on one topic because you can find something like that, but a general book oriented towards the general student of architecture, written by a mathematician but oriented towards an architecture students.

JUDY MORAN: We have lots of architects here, and if you're thinking of topics that should be included in a book that Maurizio should write, what topics would you think are really essential for an architect to know?

MARK REYNOLDS: Judy, can I speak a moment? Lurking behind the iron curtain is art, and I really haven't heard much of it here. I think that we saw a couple of pieces, But I think geometry 
is a link between the arts and the sciences. Mathematicians are over there and the artists are over there and I see a role of art here, being an artist myself, and no one is talking about the role of creativity in art. Is the architect a scientist, or is he an artist, or is he both, or is he neither? You and I know as geometers and artists that there is a role that that art plays and I'm not hearing that addressed at all, and I'm steaming.

JUDY MORAN: Can I just answer Mark for one minute because I did actually bring this up at one of our lunches. I actually think I spoke to Mario [Krüger] about this and said, "Where does aesthetics come in in architecture education? Is that the spark of genius; is that the ingrown thing? But our mission on the panel was really to discuss not the whole field of architecture but what mathematics was essential for an architect, and certainly even those of us who are patriotic mathematicians would want to suggest that mathematics is the whole story of architecture or even a major part of it, it's just that that's what our agenda here was, so it's not that mathematics is sufficient, we're just trying to decide if it's necessary. I know that here is an architect who had his hand up.

RANDY SWANSON: The answer is either more or less than what you are doing right now. It should be absolutely nothing so that the current systems in the world will eventually simply collapse. The sooner they collapse the better, because that collapse will be less damaging. The greater the mathematics that you have, the longer we are going to be able to perpetuate a system that is clogging up the earth that is over populated and that has too many people, enable us to purify and provide more water with less resources. There is an enormous application of mathematical modeling right now to double the density of Manhattan which is going to produce such a concentrated toxicity to the ocean that it is insane. But we will generate new systems to deal with those toxins so that we can double the density. You're trying in your question, in addressing the issue of education, to change the status of the profession, which is the middle layer. Of all of the students, it's the most average individual that I see as a student. And architecture students are not the brightest students anymore. It's not the profession that has the attractiveness that brings bright people to it. What I mean by this is, if you want a lot of money, you don't go into architecture.

JUDY MORAN: You don't go into teaching, either!

RANDY SWANSON: Well, unfortunately there are some of us who do both of these things. But here's the key: if you are going to actually address this rationally, even though the problems we're in were not created rationally. No rational person would say, "Well, alright, keep producing more automobiles every year." It doesn't make sense, right? The idea here is to provide the student with enough technical skill to be able to understand the new modeling methods that are demonstrating the problems that we are in, so thermodynamic computer modeling methods that actually allows a student to understand the output so they know how to change the nature of the building that they are dealing with through a series of models to improve performance. Otherwise, forget it. We can really pursue the issue of art, we are pretty good at that, we can work through it, we don't need advanced mathematics for that and we're not going to really participate in solving the problems that exist, that genuinely exist right now, into the future.

STEPHEN WASSELL: As an avid environmentalist, I appreciate the issues that you are raising, but that's way beyond the scope of this conference, don't you think?

RANDY SWANSON: It's the application of mathematics capabilities. I have students that can't understand ratio. This is insane. They are very happy to play computer games, but as soon as I 
start a series of very simple and poetic relationships in a mathematical framework, it's like I hit the off switch.

CHRISTOPHER GLASS: As an architect who teaches liberal arts students in one course, I would agree that I find most of the students not prepared with a mathematical mindset of solving architectural design problems, and I think what was said about Siza was a very good summary of this: that disciplined habits of thought, of problem solving through the desire to achieve an elegant rational solution to a problem is perhaps the greatest aspect of what mathematics can contribute to the design education, and that elegance may be the link between mathematics and art that we have been talking about.

DAVID SPEISER: Well, I was a bit puzzled by what was said by the panel members (not all of them). It seems to me that in such a discussion one has to go to the goal and then think backwards from the goal to the means. Now the goal is surely not the architect. It's the client of the architect who wants a house built, and his first condition is that the house not fall down and that it will be comfortable. Why doesn't the house fall down? As we learned in a very beautiful contribution to this conference, it is because the architect must know the laws of mechanics. First from the architect we go to mechanics and then, I am afraid, we only go to the mathematicians. So in the mechanics course you must learn what is a force, you must learn algebra of vectors, moments of forces, algebra of tensors and this will determine what mathematics and how much of it he will need. It is all very well to talk geometry and it's all very well to talk of all these beautiful things, and then there is vectors, there is algebra, there is calculus, thermodynamics, which is needed, means differential equations, and there is each time a great decision: how much of it? There are other things, more and more, the quality of the materials, that means elementary chemistry, and again, how much mathematics is needed there. That makes about the fourth generation, and then it all boils down to numbers, how much to each, I leave to you.

JEAN BRANGÉ: I want to respond to Maurizio and to José, because I'm surprised of your question, because if you a good mathematical background to keep on carrying universities to these, this is for both fields, and this can be done at college level. Why should you get your basic mathematical background, problem solving and structure of mind only when you get to university? I think it's too late. this has to be done before.

ARSÉLIO MARTINS: Two things. First thing, it's sure that all the people with independence, adults like us, know everything that we have been concerned with here at a certain level. At a certain level it's true and it's true for the architects. If it's not true, there is no culture; mathematics is a part of cultured citizens, I think, and at that certain level it's a part of culture of all citizens. I think that it's not true that mathematics is only a certain culture. It's not only the mathematics we think of when we are mathematicians. There are skills, there are methods, there are notations, there are ways of communications, there are many, many things that all citizens, including the architects, may learn. And I think that it is good to show examples and say that yes, that's mathematics. And I think that all learning is modeling and there are mathematical objects that are, at a certain level, not so deep. The drama is that we can have mathematics students and architects who don't learn any mathematics at the secondary or high school level: that's the drama.

MARIO KRÜGER: When I was presenting the slides, I was just talking about the first thing that I started with, which is Vigotsky, i.e. the problem of interconnection between the disciplines, that we don't have in our curriculum, which I believe it is fundamental to have it in a course which is directed to synthesis of doing projects and doing designs. Now I am going to answer some of the 
questions that were put here, related to Jean Piaget, the question of transformation. I quote not Âlvaro Siza, who has been quoted here widely, I say, but the professor of Álvaro Siza, Fernando Távora, who says the dictum "in architecture the opposite could be the truth". That is as we are now. And I recall that Lionel March, in the beginning of his paper in this conference started saying that "A crude but useful distinction between mathematics and architecture is that the former tends towards abstract generalisation whereas the latter is completely particular." And that reminds me one of the thoughts that Lionel told me a long time ago about induction, deduction and abduction. And this can be recalled in a very simple way: that the Pythagorean theorem is the rule and it has been, since a long time, deducted through geometric transformations. If you have one set of right triangles, and if you prove that the theorem holds for $\mathrm{n}$ triangles and you generalise it to $\mathrm{n}+1$, then you have induction. But we also have abduction. In this case the rule is given by the theorem $\mathrm{a} 2+\mathrm{b} 2=\mathrm{c} 2, \mathrm{c}$ is a solution which is given, and we are looking for an a and a $\mathrm{b}$, trying to find out which $\mathrm{a}$ and $\mathrm{b}$ fit the equation, that's abduction. And I say that in architecture that is fundamental, that's where the creative leap happens. And coming back to the conference, what I saw, the most part of the papers were very much related with induction and deduction, at least in the two first parts of it. I'd say that the very last paper by Andrew Liu, the way of how algorithmic architecture in twelfth-century China operates, it's put in a very nice way. The problems of induction and deduction are addressed. In fact Liu generates the corpus trough a deduction process, generated by above and below rules, to use Liu's words. I'd say that the generative process was also very much inductive in the sense of creating new designs that did not belong to the original corpus. And we have also in the presentations made at this conference the problem of abduction. In the paper by Randy Swanson it was addressed the problem of Claude Perrault's Observatoire of Paris. I remember that in this case the building itself is the solution, the quotation of Vitruvius, which was made by Randy Swanson, is the rule, and the equilateral triangles that he was able found to explain the proportional system used by Perrault is exactly the concrete case. Coming back to Lionel's remark that's where the abstract generalisation of mathematics and the concrete and particular of architecture meets at full strength.

So coming back to the conference, what I found is that the most part of the papers deal exactly with induction and deduction, and not with the problem of abduction. So, I say in the end, and this is the question that I am going to put to the audience, which papers do you recommend to your students?

PETER SCHNEIDER: I'm not going to answer that question, and it took me by surprise. I did want to make a comment though, John McKnight, an American sociologist, has done an extensive study of what he calls the learned professions, which mathematics and architects are a part of. He basically in the end has come to the very cynical definition of the professions. He said that the professions are those who define themselves or who characterize themselves by defining or re-defining problems that only they can solve, and made the point that that has led over the last 50 or 70 years to a loss of expertise, where the expertise associated with professions like mathematicians has been appropriated by others, has been abducted, to use that term, by others. And so in one sense I would say as to the role of mathematics within an architecture curriculum, the question is perhaps the wrong one. I think the question is what is the role of a mathematician within the architecture curriculum. And I would argue that there is a huge difference between reasoning and problem solving, and that what the mathematician brings to the architecture curriculum is an education in reasoning rather than some other people who might bring an education in problem solving, and that only through that reasoning can an architect deal with the complexities that Randy [Swanson] alluded to, because we're not going to solve the problem without being able to work at a very high level of reasoning about the problem. 
Jaime CARVAlHo E Silva: I am not an architect, I'm a mathematician, I'm an analyst and worst of all, I come from the mathematics department of the University of Coimbra. So there should be some blood, but I hope it will be an educational blood. I think that Jean Brangé was the right question. You are teaching geometry, things are useful or not useful, how many years do you need for that? Maybe only ten years, high school, 12 years till the end of high school, 14 years, 20 years, post-graduate studies and I think that that is exactly one of the origins of the difficulty, because there is not one mathematics there are several mathematics. You have calculus, linear algebra, geometry, discreet mathematics, numerical methods, statistics; , they are all different, they have different aspects, different characteristics and they are not at all trivial. You cannot just learn one topic one year and then you are done. You need to have different kind of approaches. I will quote only one example: everybody, including architects, should have some of the domain of the mathematics of chance. To know what it means to maximize, not by trial and error, but to have some idea of the methods. This you cannot learn in a small segment of time, so you need one year one approach, another year another approach, and so on. It will be impossible just to be brief, to arrive to the end of high school with all these different cases. Maybe more geometry, or in this case more mathematics for architects maybe more mathematics of change for others, but it will be difficult to have some highly technical profession without even the faintest idea of what a differential equation is. And I think what happens in our high school curriculum, what happened in the architecture department in Coimbra is that you have difficulties, you have students complaining freely, so you choose the easy way out, you just wipe out the course. Solved it! No, that is the worst of the solutions, because you are telling the students that they know something when they know less of these things. And maybe the solution or a way to some solution is one of the things that Maurizio quoted, that students do not think that what we teach is useful. Why is that? Maybe we are too much attached to the tradition of the mathematics curriculum. Maybe it is the only alternative: oligarchy or chaos? Can't we have another alternative? I think that the main point is the methodology. It is not only the content, but the methodology. There is a very nice paper by Vinicio Villani, Miguel Gusmani and others that points out that mainly at the beginning of the university curriculum that university professors fail to understand that you need to apply different methodologies and if you have different kind of students you need to think something...like, someone quoted today that our students today are different, they live in a different world, why are we maintaining our static teaching? Why do we not have more interaction with students, namely using the computer tools that are at our disposition? Why are we not using more modeling applications. One very good example is the Consortium for Mathematics and Application in the United States, it has very nice examples. To conclude, I think that all students, including architecture students, need to understand simple models and simple examples to dominate the complexity of our world and not be dominated by it, or deceived by their guise.

JUDY MORAN: I would like to bring us back a little bit, if I could. I was just actually on a committee to institute an environmental sciences major at our college and what I....every discipline of course feels that it is the essential discipline, that it has the keys to the kingdom. And it is hard for us mathematicians, because of course we are mathematicians, we love mathematics, we think that everyone should know a great deal of mathematics. But I asked before and I'll ask again, Are there some practicing architects who want to talk about what mathematics is essentially, or what they find, is useful. This is your big chance!

JAMES (JEB) BISHOP: I'll give you a perspective from being in the trenches of building things. I actually build biomedical instruments. I build the control systems for it, and I think there is a great deal of analogy with architecture. Where an architect builds a building, I'm building an 
instrument. It's a very complicated system and in the many, many pieces, the relationships are described by mathematic relationships. In my efforts to build this control system I've found probably three different kinds of people in regards to their to understanding of mathematics. On one extreme I find a lot of people who don't know mathematics at all, they have a mental block and they just can't do it. I think in Maurizio [Vianello's] terms, they are consumers; they can push the buttons, but they can't design, they can't build. On the other extreme I find people who have majored in mathematics, they have a Ph.D. in mathematics, they know matrix algebra, they know statistics, they prove theorems. These people, a lot of them, they don't do so well at applying this mathematics to the real world. When you prove a theorem, you have equations, you have $\mathrm{x}, \mathrm{y}, \mathrm{z}$. But when you go In the real-life world you have to have numbers, you make measurements, what is the $\mathrm{x}$, what is the $\mathrm{y}$, what is the $\mathrm{z}$ ? These people don't know. They can't find in the real world what that $\mathrm{x}$ is. Okay, that's the second extreme. In the middle is the kind of person who's most useful in designing this kind of automation system that we are building, is the person who does understand mathematics very well, but they've gone out of the classroom, gone out of the $\mathrm{x}, \mathrm{y}, \mathrm{z}$ and they can make measurement in the real world, a beam for example, the torsional forces on it, they can take that number, put it into the right equation and apply it and you can build something that will work and not fall down.

JUDY MORAN: Are there architect here? Yes, Chris...

CHRISTOPHER GLASS: In my real life, I build buildings; I do my mathematics for recreation, as my article in the journal, as my article in the [Nexus Network] Journal shows. But it is the case that architecture, as in the trenches, as practicing, means knowing a lot about the procedures by which things get done, and most of those do not involve mathematics. Most of those involve politics; most of those involve the politics of economics, how you can convince people to spend the money to build buildings. And for most of these mathematics can be useful as advertising in the sense that you can say, "My building is more carefully constructed mathematically than the neighbor's down the street." I think we've heard Frank Gehry kicked around a lot this week because his buildings appear to be extremely complex and they are only just difficult; they don't have any kind of elegance to the mathematical structure, they are simply complicated to build. I think the difference between those two ideas is one way the notion of using mathematics in a disciplined way could be fruitfully sold to architecture students: to say, you can build more complex, interesting structures which you can then get built, which is the whole purpose of architecture, to get buildings built, despite what many people write about architecture. And therefore mathematics is always used as a means to the end and only one of the means to the end, and I think that's one reason you see the hostility from the architects to the mathematicians in the curriculum, and one reason that communicates itself to the students in the form of the architecture students telling you," Oh well, this isn't necessary for me to get on with my profession. I entirely agree with the definition of "profession" that we've just heard, that basically you try to set up a secret society in which you have the only keys that you can open the locked society with. So I think that while we are trying to create an ideal world where mathematics is central to the process, I think it is important to realize that the process is really a political one of getting things built.

JUDY MORAN: Thank you. Jean?

JEAN BRANGÉ: Yes, because I am an architect and I have built and I have been using computers, so I am not defending my computer part, but talking about [the political process of getting things built]. My experience for the last ten years is that I was able to use complex mathematic objects to help me build things, but these were very expensive, high-tech objects and

98 NeXus 2002 Round TABLE - Mathematics in the Architecture Curriculum 
the clients were willing to pay a lot of money for their design. And when it comes to more basic objects like housing and things like this, the use that I made of mathematics in the office were modeling which has to do with economics of a certain thing, how to be able to prove that what you are doing, to show that you get numbers which can be economic, so areas and something like this which show that your design is going in the correct way and that you are better than the other one or something like this. So that is the way I could use mathematics, but it's not that complex, just simple calculations. When I needed to use mathematics as geometry or creating shapes or as space tool or mathematical objects, this could only be done on very expensive projects, that's my experience.

KIM WiLliams: I was a practicing architect, and when I was working in Philip Johnson's offices he was doing buildings that were not rectangular and no one in the office knew how to do an area takeoff on those shapes. It was a complex problem. I had a reputation in the office as being very mathematically inclined because I had the patience to sit there and figure out how you did the area takeoff on these shapes. And it was very embarrassing because I was sure that someone was going to find out that I'm really not mathematically inclined, I'm only very patient! So as to what Jean was just saying, it's simple mathematics, but area takeoffs, when it comes to economics, and you have to show your developer that you have enough usable square footage to make this building a profitable rental property, we need to know this. And actually it helps us get out of the traps of rectangular buildings because, you know, I bet there are a lot of architects who have dumbed down their buildings so they can do these kinds of calculations. It's a very banal thing, but in the end it leads to a banal environment.

JEAN BRANGÉ: I want to add that this can happen at a very beginning stage of the design process. As an example I use these things at the very beginning stage, it's the first thing I drew (I'm using computers only without pencil and paper) and I tried to use as much as I could of economics and techniques that I could use from the output of the computer to prove that I am doing is going in the right direction, and also to help me design. For example, I was able know the place of my design where I should concentrate my study because that was where I was losing space or I was losing money or something like this, from the beginning of the project, not at the end, not when you need to know how much it costs. You can do it at the very early stages and this changes the way you design, changes the way you produce your design.

KIM WILLIAMS: But what about the case that Lionel was talking about the other day, about increasing the surface area of a building, whether you want to increase it for environmental reasons or you want to increase it to give people more window space, or to optimize the views. That's a kind of mathematics that may be elemental, but to an architect is really very useful and fundamental.

JUDY MORAN: We have five minutes to make a conclusion.

LIONEL MARCH: Essentially I've been thrown out of the architecture department for what I teach. And now I'm an independent professor at the University of California, which is actually really rather wonderful; I don't have to deal with any departmental politics. But I do have architectural students who come to my classes; it's not required but they do come. And I think, what I try to do over three terms, say 180 hours in a course of fundamentals of architectonics, is introduce them to a range of mathematical ideas so they become familiar that these ideas exist in the world and point out that they can be applied in certain ways; that there are certain architectural applications and therefore at some point in their lives they might come across a problem or situation which they know, "Ah, that might work, we might find someone who thinks 
along those lines", or "I might go to a book and remember, my notebook, and so recall how something works." I teach this with a lot of enthusiasm because I think one thing you need in to do in education is enthuse the student, to get them excited about ideas. I'm not sure that the technicalities are all that important, especially in a field like architecture, you don't have the time for all that. The other thing that ties in with a very good point you were making about the nature of society: we talk always about architects solving problems, who sets the problem in the first place? And frankly I'm pretty pissed off with some of the people who are setting those problems. So therefore my direction, and it was reflected in my paper, was to open up and to show the students there are many, many different kinds of opportunities. And that's, rather than solving problems, that's providing or looking at the possibilities. And then it will be for society and politics or so on to say, "Well maybe this is not the only way to do something," and I absolutely agree with you we are doing things now that we are doing things now which are often very hightechnology, require a lot of computing, a lot of mathematics, which are going to be disastrous in all kinds of ways. And I do think that we can show that that's not the only direction, through this sort of understanding and enthusiasm, which need not be mathematics in a technical sense, but has that understanding, the ideas coming out of a sort of mathematical way of thinking.

ROBERT TAVERNOR: Can I add to that in a slightly different way, in that I'm an architect and a historian, but not a very good mathematician. What I learned about mathematics has come via Vitruvius and particularly Alberti, who even wrote a small treatise on mathematics. When he talks about mathematics in his treatise on architecture, which is a much more major work, he talks about it in two ways: he talks about it in terms of quantity, which is concerned with the measuring of areas of models and so on, and he also talks about it in terms of quality. Thus, he talks about the importance of measuring buildings, of the experience of measuring buildings, so that there is that one-to-one relation with things: that numbers are not just abstract things, they describe qualities too. And he particularly talks about the quality of number in a universal sense, in terms of its relationship to ourselves and the meaning of number beyond ourselves. So I think it's very difficult to teach mathematics to architects today without also emphasising the quality of number. Understanding these qualities comes only through experience.

JUDY MORAN: We are almost out of time, but I just want to refer to, I'm not sure where I read it, it might have been Rumiko's paper, I might suggest this to Kim as an appropriate topic for the Nexus 2004 round table, which is the question, "With new technology we can build it, the question is, Should we build it?" That might be a good topic, I think that this is in some ways what we are getting at here.

STEPHEN WASSELL: Kim, do you welcome e-mail responses?

KIM WiLliams: Yes, we would love e-mail responses. We are going to transcribe this round table and get it on the Internet as soon possible and I would welcome e-mail responses to that and we'll put them up online as addenda to the round table discussion, and there's no reason why in that way we can't just keep the discussion going. Thanks everybody, thanks to our panel. 